\title{
Exploring the Critical Success Factors for Effective Implementation of the ISO 9001 Quality Management System
}

\author{
${ }^{1}$ Mahmoud Aburas, ${ }^{2}$ Angela Lee \\ ${ }^{1}$ University of Salford, School of Science, Engineering and Environment, Salford, UK. \\ ${ }^{2}$ University of Salford, School of Science, Engineering and Environment, Salford, UK.
}

Correspondence Author: Mahmoud Aburas, University of Salford, School of Science, Engineering and Environment, Salford, M5 4WT, UK E-mail: M.Aburas@edu.salford.ac.uk

Received date: 15 September 2019, Accepted date: 12 December 2019, Online date: 31 December 2019

Copyright: (c) 2019 Mahmoud Aburas, Angela Lee, This is an open-access article distributed under the terms of the Creative Commons Attribution License, which permits unrestricted use, distribution, and reproduction in any medium, provided the original author and source are credited

\begin{abstract}
Background: Interest in quality began to emerge during the 1940s, where companies from various sectors started to incorporate quality systems while establishing specific criteria for their suppliers' compliance. This sporadic approach led to the creation of barriers to trade resulting from inconsistent characteristics and quality standards, and thus the introduction of common standards was required to satisfy the client's requirements, as realized by the International Organization for Standardization (ISO). Quality management under ISO 9001 is globally accepted and has moved into other sectors, including the construction industry. Nevertheless, research has revealed that project managers tend to consider the primary benefit of quality management systems (QMSs) as marketing and procurement tools, with challenges identified regarding the implementation.

Objective: This study seeks to explore the critical success factors (CSFs) for the successful implementation of the ISO 9001 QMS in UK construction projects.

Methods: A review of the literature on QMSs, ISO 9001 and the UK construction industry were conducted. Then, semistructured interviews were carried out with six project managers from UK construction companies to explore their perceptions on ISO 9001 implementation through content analysis.

Results: The findings of this research confirm a set of seven CSFs (i.e. client focus, engagement of people, leadership, the process approach, relationship management, continuous improvement, and change management) as being vital to the successful implementation of the ISO 9001 QMS in UK construction projects.

Conclusion: This study identifies seven CSFs for the successful implementation of the ISO 9001 QMS in the UK context, six of which are established quality management principles (QMPs), while the seventh, change management, represents a CSF that has potential for inclusion in future revisions of the QMS as a QMP, thus contributing to the quality management literature in general, and specifically from a UK perspective.
\end{abstract}

Keywords: critical success factor, ISO 9001, project management, QMS, quality management principle, quality management system.

\section{INTRODUCTION}

Construction projects in the UK face diverse challenges such as unskilled workers, low profitability and insufficient R\&D investment (Shearer et al., 2018). Meanwhile, industry clients frequently express poor levels of satisfaction with the service provision and final quality outcome (Proverbs et al., 2018). Construction is an important contributor to growth, adding $£ 117$ billion to the UK economy in 2018, as well as 2.4 million jobs in the second quarter of 2019, representing $6.6 \%$ of all UK employment (Rhodes, 2019). Meanwhile, quality is a vital facet of projects that promotes success and sustained growth (Natarajan, 2017). Nevertheless, quality is subjective. Rumane (2018) underscored that quality in construction projects differs from other sectors due to the unique outcomes. Quality does not imply the state of perfection, having a strong relationship to cost, the market, and technology (Mukherjee, 2019). The focus of this paper is placed on ISO 9001, a widely accepted standard for quality management systems (QMSs) worldwide. Despite no mandatory requirement for its application, there is increasing interest in the implementation of ISO 9001 (ISO, 2017). Since myriad factors can influence the successful outcome of UK construction projects (Hameed and Abbott, 2017), the current study seeks to identify critical success factors (CSFs) for effective implementation of the ISO 9001 QMS in UK construction projects. 
Construction projects can be defined as non-permanent activities with a unique and temporary aim achieved through gradual progress (Schwalbe, 2015). In terms of construction companies, the management of quality implies maintaining a specified standard of quality to ensure client satisfaction, representing the ultimate motive of ISO 9001 (Hoyle, 2018). However, challenges present during the management of construction projects that may lead to project failure, delays, running over budget or unsatisfactory quality (Schwalbe, 2015). Project management thus requires skill, precision, and tact, and entails balancing competing stakeholders' demands (i.e. cost, quality, scope, and time) with the recognised expectations and requirements (Dumitrascu and Nedelcu, 2012).

The key competitiveness component of construction projects is quality, which Rumane (2018) defined as satisfying the client's needs, ensuring the project/product/service outcome is fit for purpose and meets the specified requirements. The management of quality is thus a vital project management role. Nevertheless, with contractors typically selected based on price (Harrington et al., 2012), additional threats arise. Therefore, QMSs were created by national and international institutions that extend beyond mere quality control to embrace quality assurance (Mukherjee, 2019).

Representing a philosophy for management that entails all quality facets of interest to clients and organisations, the QMS is a credible means of reducing costs and enhancing productivity, while promoting improved quality (Criado and Calvo-Mora, 2009). ISO 9001:2015 defines the requirements for a QMS, whereby the organisation (i) must show its ability to provide products/services that consistently meet the client's/regulatory requirements, and (ii) aims to improve client satisfaction through effective QMS implementation (Dentch, 2016). In ISO 9001:2015, seven quality management principles (QMPs) were developed: (i) client focus, (ii) leadership, (iii) engagement, (iv) process approach, (v) improvement, (vi) decisions based on evidence, and (vii) managing relationships. Since 1987, the ISO 9001 standard has become widely accepted, with over one million certifications by the 2016 year-end (ISO, 2017).

\section{CSFs for ISO 9001 implementation}

Bullen and Rockart (1981) described CSFs as signposting where positive results are essential for managers to achieve their objectives. Therefore, with great value attached to identifying areas that can promote successful project outcomes, this study explores factors that may be considered critical to the successful implementation of ISO 9001 in UK construction projects.

Construction projects are typically unique endeavours that are increasingly complex and technical (Rumane, 2018). Therefore, the incidence and complexity of change is ever present. ISO 9001:2015 offers guidance on change management regarding measures applicable to allow organisations to methodically plan and modify the QMS to enable timely reactions to changes in circumstance, client requirements, competition, organisational strategies, and regulatory requirements (Abuhav, 2017). The desired outcome is ensuring change can be addressed without any negative impact on quality (Mukherjee, 2019).

Client focus is an established QMP (Fonseca and Domingues, 2017), with Hoyle (2018) asserting that client-focused organisations aim to fulfil the client's needs/expectations to enhance client loyalty and increase the likelihood of success. Abuhav (2017) reported that ISO 9001:2015 establishes three primary goals for clients and their expectations: (i) the comprehension and implementation of the clients' and regulatory requirements, (ii) developing a strategy that links to the clients' needs/expectations, and (iii) producing an outcome that meets the clients' and regulatory requirements.

In terms of the engagement of people QMP, Fonseca and Domingues (2017) reported a shift from the passive 'involvement of people' in ISO 9001:2008 to the more active 'engagement of people' in ISO 9001:2015, where the change in terminology implies stronger participation and the emphasis on competence. Moreover, there is a requirement for competent, empowered and engaged staff organisation-wide to increase value creation and delivery capability (Fonseca and Domingues, 2017). The belief is that engaged people will align with their leadership, where the personnel experience a personal and emotional connection to the organisation, and a closeness to its actions, ethics and values (Hoyle, 2018).

Hoyle (2018) asserted that organisational culture, motivation and vision emerge from the leadership, who create the vision through their decision-making and action, which drives employee motivation. Meanwhile, under ISO 9001, leadership generates the organisational momentum and direction, creating an internal environment whereby personnel can fully engage with the achievement of the organisational objectives (Mukherjee, 2019). Under this ISO 9001:2015 QMP, leaders are required to provide evidence of their commitment, such as practicing and demonstrating leadership, establishing a quality policy and objectives, and ensuring the QMS's effectiveness (Abuhav, 2017).

Fonseca (2015) stated that while the system approach to management can be found under ISO 9001:2008, in the ISO 9001:2015 revision, systems and processes are now located under the process approach QMP, which addresses how related processes can be managed. The 2015 standard harnesses the process approach, enabling the organisation to effectively plan its processes and associated interactions, with the organisation's effectiveness being dependent upon its ability to simultaneously conduct a range of interconnected actions (Abuhav, 2017).

The relationship management QMP emerged in ISO 9001:2015 (Fonseca, 2015). Hoyle (2018) described organisations applying this principle as those who (i) comprehend which relationships are essential for success, (ii) recognise which relationships may threaten success, (iii) develop short-term and long-term relationships, (iv) ensure clear and transparent communication, (v) share information and future plans where appropriate, and (vi) recognise the achievement of those who have contributed to the organisation's success.

The continuous improvement QMP defines the long-term objectives of the organisation in terms of performance, whereby organisations should apply a comprehensive approach and ensure that every individual is committed to on-going improvement (Manders et al., 2016). Rather than representing an activity, improvement is actually an objective/outcome. Therefore, while activities can be planned and implemented, enhanced improvement can only be confirmed through the evaluation of outcomes (Hoyle, 2018). 
From this literature review, seven CSFs were identified for further investigation: change management, client focus, engagement of people, leadership, process approach, relationship management, and continuous improvement.

\section{METHDOLOGODY}

Semi-structured interviews were conducted with project managers selected purposefully from UK construction companies engaged as contractors, with the aim of exploring the seven CSFs that emerged from the literature review. Six project managers were interviewed through face-to-face semi-structured interviews carried out from June to August 2019. Content analysis was applied to the interview transcripts, as this is particularly suited to analyzing such qualitative data (Easterby-Smith et al., 2015) and coding the different parts (Schreier, 2014). A manual coding frame was developed, with the seven factors labelled as categories $\mathrm{A}-\mathrm{G}$. The content analysis process comprised of reading and re-reading the transcripts, and allocating codes that linked to the aforementioned categories until every relevant chunk of data had been categorized (Robson and McCartan, 2016).

\section{RESULTS \& DISCUSSION}

This section presents the results and discussion of the findings emerging from the interviews, with excerpts included to add texture to the analysis.

Change management: Changes are inevitable throughout the construction project lifecycle (Ajayi and Mohamed, 2015), which are typically associated with cost and time overruns, conflict, and rework. Three participants (P4-P6) mentioned the need to plan for change, with processes needed that enable desirable changes to take place while preventing their undesirable counterparts (Hoyle, 2018). Participant 2 raised the need for proactive change management, declaring: "If you fail to plan, you plan to fail". Meanwhile, Participant 3 asserted the promotion of continual improvement to remain competitive, which aligns with Rumane (2018). The importance of educating stakeholders on the negative outcomes of unnecessary change was confirmed by Participant 1, who cautioned his clients on the cost/time implications. Such awareness raising is important as clients may not return for future work if they are dissatisfied with the product/service provided (Hoyle, 2018). Participant 5 stated that if change is required "everyone in the team needs to get involved", while Participant 6 believed that collaboration within the team is vital, since avoiding conflict and promoting teamwork is vital (Natarajan, (2017).

Client focus: ISO 9001 emphasises leadership and commitment to ensure that top management meet the clients' and regulatory requirements (Abuhav, 2017). Participants 2, 5 and 6 underscored the need to understand the requirements of current clients to ensure future work, recommendations, and an enhanced reputation. Moreover, Participant 6 emphasised understanding future clients' requirements, whereby "to win future work we need to have a good quality standard". This echoes the importance of comprehending the requirements of current and future clients (Luburić, 2015), alongside Rumane's (2018) emphasis on ultimately enhancing client satisfaction. Participant 5 described his organisation's efforts to ensure the project's objectives match the client's requirements by reviewing the client's needs and then submitting the contractor's proposal, with Participant 3 highlighting the importance of such objectives meeting the client's expectations, "They are top of the food chain", as these are central to successful project outcomes. Both responses underscore the importance of synergy between the project's objectives and the client's requirements/expectations (Fonseca and Domingues, 2017). Essentially, the client's requirements can be either asserted, implied, or statutory obligations (Hoyle, 2018).

Engagement of people: ISO 9001:2015 states that engaged, empowered, and competent people are required to promote the organisation's ability to generate and deliver value (Hoyle, 2018). Several participants agreed with the need to facilitate the open discussion of quality issues amongst the project team, for example, "We have frequent discussions regarding any issues facing us in the project lifecycle" (P1). It is therefore important to create an open forum to address problems that arise (Fonseca and Domingues, 2017). Meanwhile, Participant 3 focused on the need to emphasise the staff's wellbeing: "We try and help everyone". This echoes the claim that top management should promote engagement to facilitate the QMS's effectiveness (Abuhav, 2017), and employees' motivation enhanced to sharpen their focus on the organisational values and project goals (Mansour et al., 2019). Participants 1 and 3 asserted the need to engage people with ideas and groupthink, while encouraging their perspectives, highlighting the importance of encouraging openness and objectivity to promote responsible behaviours (Luburić, 2015).

Leadership: ISO 9001:2015 encourages effective leadership to ensure the effective implementation, maintenance, and continual improvement of the QMS (Natarajan, 2017). Participant 1 focused on the need for good project awareness and effective preparation by leaders, which agrees with Dentch's (2016) claim that under ISO 9001:2015 the leadership is responsible for creating the project's vision, and the pathway via the strategic direction. Creating trust with employees was a popular theme, with Participant 4 asserting. "If you are a good leader, people follow", and Participant 5 expressing the importance of humility to recognize that mistakes enable professional growth. Total quality involves everyone in the organisation (Rumane, 2018), and thus trust between employees and managers is desirable. Meanwhile, leaders should demonstrate their commitment to the role (Mansour et al., 2019), with Participant 2 cautioning: "It's got to be the most important thing". Finally, Participants 1 and 5 raised the need for coaching leadership (Berg and Karlsen, 2016), whereby the project managers seek opportunities to promote the long-term development of their team to facilitate project success. Essentially, leadership is vital to ensuring organisational success (Luburić, 2015).

The process approach: Facilitating the organisation's planning of processes and their interactions (Abuhav, 2017), the process approach enables auditors to determine established processes' compliance with the stipulated standards, policies, and procedures (Rumane, 2018). Two of the participants (P1 and P3) raised the issue of risk, and the need to take action to address it, 
with ISO 9001:2015 featuring a shift towards addressing risk-based threats (Fonseca, 2015). Meanwhile, ensuring that activities are managed as processes was raised by four project managers and highlighted by Sickinger-Nagorni and Schwanke (2016). Participant 3 referred to the importance of following the programme of works, "You've got to adhere to it", while Participant 5 highlighted the ability of processes to support future projects. The links that exist between activities should be determined (Chiarini, 2017), with Participant 2 addressing this point by underscoring the importance of monitoring for strong awareness of when processes can be started and completed.

Relationship management: The main benefits of relationship management are value creation, effective responses to change, and the optimization of costs and resources (Luburić, 2015). Three participants (P1, P3 and P6) discussed informationsharing with stakeholders, supporting the assertion that stakeholder relation management involves the dissemination of goals, knowledge, values, and understanding (Sickinger-Nagorni and Schwanke, 2016). Meanwhile, regarding sharing plans with stakeholders, Participant 5 encouraged honesty and transparency, "You need to be very open with your client", as affirmed by Hoyle (2018). Cooperation in the development of activities is vital (Hola, 2015), which was echoed by Participant 3 who noted the project manager's central role. The importance of ensuring good stakeholder relationships was also raised, with Participant 2 reporting that "I always have an open-door policy", while Participant 3 referred to the importance of being personable. Mansour et al. (2019) concurred with the importance of good stakeholder relationships through the results of their questionnaire survey.

Continuous improvement: Aligning all organisational staff toward continual improvement (Fonseca, 2015) is vital to facilitate meeting the clients' requirements, while enhancing client satisfaction and achieving the quality objectives (Abuhav, 2017). Meanwhile, the project team should be encouraged to participate in improvement (Mansour et al., 2019), as asserted by Participant 4: "We all can improve". In this context, Participant 3 cited the regular team meetings, while Participant 6 underscored the progress that can be made by learning from mistakes. Then, in terms of analyzing performance (Willar et al., 2015), Participant 1 noted that to achieve successful outcomes he would regularly identify and revise performance. Participant 3 discussed the importance of using each project experience to inform and improve the next, while Participant 2 focused on the positive impact that cooperation has on increasing the productivity, "We need to make sure that the productivity keeps improving ... through communication and teamwork". In terms of human resources management, the internal benefits of ISO 9001:2015 include improved participation, satisfaction, and motivation, alongside reduced absenteeism (Prado-Roman et al., 2018).

Table 1. Summary of the confirmed CSFs and factor components

\begin{tabular}{|c|c|}
\hline $\mathrm{CSF}$ & Associated factor component \\
\hline \multirow{4}{*}{ Change management } & Plan for change \\
\hline & Promote continual improvement \\
\hline & Educate stakeholders on the negative outcomes of unnecessary change \\
\hline & Embrace the change as a team \\
\hline \multirow{2}{*}{ Client focus } & Understand the current and future clients' requirements \\
\hline & Ensure the project objectives match the client's requirements and expectations \\
\hline \multirow{3}{*}{ Engagement of people } & Facilitate the open discussion of issues \\
\hline & Enhance the motivation of personnel \\
\hline & Involve people and encourage their perspectives and groupthink \\
\hline \multirow{4}{*}{ Leadership } & Establish a vision and pathway for the project \\
\hline & Create trust with employees \\
\hline & Ensure commitment to the role \\
\hline & Coach personnel to release their potential \\
\hline \multirow{3}{*}{ The process approach } & Take action to address risk \\
\hline & Determine the links between activities \\
\hline & Manage activities as processes \\
\hline \multirow{4}{*}{ Relationship management } & Share information with stakeholders \\
\hline & Cooperate in the development of activities \\
\hline & Share plans with stakeholders \\
\hline & Promote good stakeholder relationships \\
\hline \multirow{3}{*}{ Continuous improvement } & Analyze performance \\
\hline & Enable the project team to participate in improvement \\
\hline & Engage in effective teamworking \\
\hline
\end{tabular}

\section{CONCLUSION}

This paper analysed the qualitative responses that emerged from interviews with six project managers, with the aim of identifying CSFs for effective implementation of the ISO 9001 QMS in UK construction projects and explaining how these CSFs manifest in the project managers' milieu. Of the seven confirmed CSFs, six echo those presented in the literature as QMPs in ISO 9001:2015, that is, client focus, engagement of people, leadership, the process approach, relationship management and 
continuous improvement (Fonseca and Domingues, 2017), with change management found to be an additional CSF that has potential for inclusion in future revisions of the ISO 9001 QMS as a QMP. This study demonstrates the value of exploring the real-life experiences of project managers to confirm the on-going relevance and add further definition to the CSFs for the successful implementation of the ISO 9001 QMS in UK construction projects, their components, and the ISO 9001 QMPs.

This study supplements the research and practical guidance on implementing the ISO 9001 QMS in UK construction projects, whereby the contribution to knowledge is the CSFs and factor components that emerged, along with a new QMP to be considered for addition to future revisions of the QMS.

\section{LIMITATIONS AND RECOMMENDATIONS}

This study focused on UK-based construction project managers only, and thus the findings may be less generalisable to non-UK settings. Moreover, some of the identified CSFs may become invalid at a future date, and so this study may need to be repeated periodically to ensure the continued relevance of the findings. Future work should consider the investigation of such CSFs in other national contexts, both in the developed and developing world.

\section{ACKNOWLEDGEMENT}

The authors express their sincere thanks to the project managers who participated in this study, as well as to their organizations.

\section{Conflict of Interest:}

The authors declare no conflict of interest.

\section{Ethics Committee Approval:}

Ethics approval for the collection of the interview data utilized in this research was received from Salford University's Research, Innovation and Academic Engagement Ethical Approvement Panel.

\section{Authors' Contributions:}

Mahmoud Aburas and Angela Lee contributed to the design and implementation of the research, the analysis of the results and the writing of the manuscript.

\section{REFERENCES}

Abuhav, I. 2017. ISO 9001:2015. A Complete Guide to Quality Management Systems. CRC Press. DOI: $10.1201 / 9781315369808$

Ajayi, A. A., and S. J. Mohamed, 2015. Time Performance Audit of Change Management Capability Maturity of Contracting Organization. International Journal of Engineering and Innovative Technology, 5(4): 34-40. Retrieved from http://www.ijeit.com/Vol\%205/Issue\%204/IJEIT1412201510_07.pdf on 15 ${ }^{\text {th }}$ January 2020.

Berg, E. M., and J. Karlsen, 2016. A study of coaching leadership style practice in projects. Management Research Review, 39(9): 1122-1142. DOI: 10.1108/MRR-07-2015-0157

Bullen, C., and J. Rockart, 1981. A primer on critical success factors. CISR No. 69. Sloan WP No. 1220-81. Sloan School of Management, Massachusetts Institute of Technology, Cambridge, MA. Retrieved from https://www.researchgate.net/publication/5175561_A_primer_on_critical_success_factors on $4^{\text {th }}$ May 2019.

Chiarini, A. 2017. Risk-based thinking according to ISO 9001: 2015 standard and the risk sources European manufacturing SMEs intend to manage. The TQM Journal, 29(2): 310-323. DOI: 10.1108/TQM-04-2016-0038

Criado, F., and A. Calvo-Mora, 2009. Excellence profiles in Spanish firms with quality management systems. Total Quality Management, 20(6): 655-679. DOI: 10.1080/14783360902924366

Dentch, M. P. 2016. The ISO 9001:2015 Implementation Handbook: Using the Process Approach to Build a Quality Management System. ASQ Quality Press. Ltd.

Easterby-Smith, M., R. Thorpe and P. R. Jackson, 2015. Management and business research. $5^{\text {th }}$ edition. Sage Publications

Fonseca, L. 2015. From quality gurus and TQM to ISO 9001:2015: A review of several quality paths. International Journal for Quality Research, 9(1): 167-180. Retrieved from https://doaj.org/article/f7cbd0b4cac545e68c0162e87063b822 on $16^{\text {th }}$ September 2019.

Fonseca, L., and J. P. Domingues, 2017. Listen to ISO 9001:2015 for organizational competitiveness: Correlation between change management and improvement. Proceedings of the $11^{\text {th }}$ International Conference on Business Excellence. pp: 916-926. DOI: $10.1515 /$ picbe-2017-0097

Hameed, W., and C. Abbott, 2017. Critical review of the success factors of strategic alliances in the UK construction industry. $13^{\text {th }}$ International Postgraduate Research Conference (IPGRC), 14-15 September 2017, University of Salford, UK. Retrieved from http://usir.salford.ac.uk/43913/ on $15^{\text {th }}$ June 2019.

Harrington, H. J., F. Voehl and H. Wiggin, 2012. Applying TQM to the construction industry. The TQM Journal, 24(4): 352362. DOI: $10.1108 / 17542731211247373$. 
Hola, B. 2015. Identification and evaluation of processes in a construction enterprise. Archives of Civil and Mechanical Engineering, 15(2): 419-426. DOI: 10.1016/j.acme.2014.11.001

Hoyle, D. 2018. ISO 9000 Quality Systems Handbook-updated for the ISO 9001: 2015 standard: Increasing the Quality of an Organization's Outputs. $7^{\text {th }}$ edition. Routledge. DOI: $10.4324 / 9781315642192$

ISO. 2017. The ISO Survey of Management System Standard Certifications 2016. Retrieved from https://www.accredia.it/app/uploads/2017/09/ISO_Survey_2016.pdf on 26 ${ }^{\text {th }}$ March 2019.

Luburić, R. 2015. Quality management principles and benefits of their implementation in central banks. Journal of Central Banking Theory and Practice, 4(3): 91-121. DOI: 10.1515/jcbtp-2015-0013

Manders, B., H. J. De Vries and K. Blind, 2016. ISO 9001 and product innovation: A literature review and research framework. Technovation, 48-49: 41-55. DOI: 10.1016/j.technovation.2015.11.004

Mansour, H., W. Aziz and E. H. Said, 2019. Influence of Quality Management Principles on Employees' Performance in First Class Hotels: A research in Alexandria City. International Journal of Heritage, Tourism, and Hospitality, 12: $442-461$. DOI: 10.21608/ijhth.2019.32004

Mukherjee, S. P. 2019. Quality: Domains and Dimensions. Springer Nature Singapore Pte Ltd. DOI: 10.1007/978-981-131271-7

Natarajan, D. 2017. ISO 9001 Quality Management Systems. Springer International Publishing AG. DOI: 10.1007/978-3319-54383-3

Prado-Roman, C., C. Del Castillo-Peces, C. Mercado-Idoeta and J. Del Castillo-Peces, 2018. The Effects of Implementing ISO 9001 in the Spanish Construction Industry. Cuadernos De Gestión, 18(1): 149-171. DOI: 10.5295/cdg.140507cd

Proverbs, D. G., G. D. Holt and H. Y. Cheok, 2018. Construction Industry Problems: The Views of UK Construction Directors. Built Environment Research Unit, School of Engineering and the Built Environment, University of Wolverhampton. Retrieved from http://www.arcom.ac.uk/-docs/proceedings/ar2000-073-081_Proverbs_Holt_and_Cheok.pdf on 10 ${ }^{\text {th }}$ September 2019.

Rhodes, C. (2019). Construction industry: statistics and policy. Briefing Paper No. 01432. House of Commons Library. Retrieved from https://researchbriefings.parliament.uk/ResearchBriefing/Summary/SN01432 on $13^{\text {th }}$ January 2020.

Robson, C., and K. McCartan, 2016. Real World Research. $4^{\text {th }}$ edition. Chichester: John Wiley \& Sons.

Rumane, A. R. 2018. Quality Management in Construction Projects. $2^{\text {nd }}$ edition. CRC Press. DOI: 10.4324/9781315098425

Schreier, M. 2014. Qualitative Content Analysis. In: Flick, U. (Ed.) The Sage Handbook of Qualitative Data Analysis (pp. 170-183). London: Sage Publications Ltd. DOI: 10.4135/9781446282243

Schwalbe, K. 2015. Information technology project management. $8^{\text {th }}$ edition. Cengage Learning.

Shearer, L., D. Morrison, S. Beale, B. Hare, J. Keenan, J. Logan et al., (2018). Supervisory Skills Gaps within the UK Construction Industry. BCTG Construct. Retrieved from http://bctgconstruct.co.uk/wpcontent/uploads/resources/bctg_skills_gap_pub.pdf on $4^{\text {th }}$ July 2019.

Sickinger-Nagorni, R., and J. Schwanke 2016. The new ISO 9001: 2015: Its opportunities and challenges. Bachelor's thesis, Tampere University of Applied Science, Pirkanmaa, Finland. Retrieved from https://pdfs.semanticscholar.org/eafa/330e84c8748fdb8f8ea68c301f28b60476f7.pdf on $16^{\text {th }}$ November 2019.

Willar, D., V. Coffey and B. Trigunarsyah, 2015. Examining the implementation of ISO 9001 in Indonesian construction companies. The TQM Journal, 27(1): 94-107. DOI: 10.1108/TQM-08-2012-0060

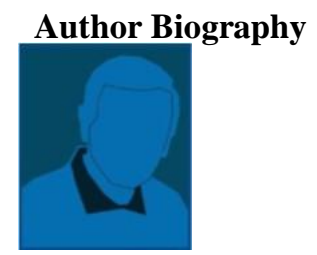

Mahmoud Aburas is a PhD candidate at the University of Salford's, School of Science, Engineering and Environment, currently in his final year of the program. His research inte 